\title{
What factors support the early age patterns of fertility in a developing country: the case of Kyrgyzstan
}

\author{
Konstantin Kazenin $^{1,2, *}$ and Vladimir Kozlov ${ }^{2}$
}

\section{Abstract}

We analyse the socio-economic and cultural factors that influence the timing of the first birth in Kyrgyzstan. As in several other developing countries in Central Asia, no trend towards the postponement of fertility has been observed in Kyrgyzstan. This contrasts not only with the current trend towards later parenthood that has been documented in highly developed countries, but with an incipient trend towards a delay in the timing of the first birth that has been reported in many developing countries. Our study is based on the Multiple Indicators Cluster Survey - 2014 (MICS2014), with complementary data drawn from the Demography and Health Survey - 2012 (DHS2012). Our analysis of the first union and of the first birth in a union for cohorts of women born between 1965 and 1998 showed that the rates of union formation and motherhood have increased among the younger cohorts. We also found that a woman's education, labour market experience, and the gender relations in her family influenced her likelihood of transitioning to a first union and to motherhood. In addition, we uncovered significant differences in the timing of motherhood and union formation between women of different ethnicities, and looked at the factors that may have contributed to these differences. The factors that support a stable age pattern of fertility in Kyrgyzstan are of interest when conducting broader comparative research on fertility timing in developing countries, as these factors may help explain the current diversity in these patterns.

Keywords: fertility timing; fertility postponement; age at first birth; developing countries; Central Asia

\footnotetext{
${ }^{1}$ Russian Academy for National Economy and Public Administration, Moscow, Russia

${ }^{2}$ National Research Institute - Higher School of Economics, Moscow, Russia

${ }^{*}$ Correspondence to: Konstantin Kazenin, kz@ ranepa.ru
} 


\section{Introduction}

Issues surrounding fertility timing and how it is changing have attracted considerable attention in demographic research. In the highly developed countries, fertility postponement is considered as one of the central demographic trends of recent decades that are associated with the "Second Demographic Transition" (Lesthaeghe 2010). In developing countries, trends in fertility timing have been less clear. In a study of a large sample of developing countries in the 1980-1990s, Bongaarts (1999) found an increasing trend in the mother's mean age at first birth (MAB1). Bongaarts et al. (2017) confirmed this general tendency for more recent decades, and argued that it has been related to growth in educational levels in the developing world. However, studies for individual developing countries have suggested that the timing trends in the transition to motherhood have varied considerably since the turn of the century (see Section 2). In some developing countries, the age patterns of fertility have remained stable even though total fertility has fluctuated, whereas in other developing countries, fertility has even undergone a "rejuvenation". This makes the question of what factors have been influencing fertility timing in developing countries especially relevant.

In this study, we consider this question mainly by examining the influence of economic and cultural factors while focusing on Kyrgyzstan, a post-Soviet country in Central Asia. This case study is of broader interest for two reasons. First, like other countries in Central Asia, Kyrgyzstan has not experienced a trend towards first birth postponement. Second, the country has a multi-ethnic character, and the considerable socio-economic and cultural differences between its ethnicities also affect their union formation and childbearing patterns. The research on ethnic diversity in family behaviour has a wider relevance, as ethnicity is an important differentiating factor in demographic behaviour in many developing countries.

The paper is organised as follows. Section 2 gives an overview of recent research on the timing of fertility in developing countries, and outlines our hypotheses regarding the factors that influence the MAB1 in these countries. Section 3 provides basic information on social development and fertility trends in Kyrgyzstan, focusing on the post-Soviet period. Section 4 outlines the data we used, and Section 5 presents an analysis of first union and first birth timing in relation to selected economic and cultural factors. Since levels of out-of-union fertility are extremely low in Kyrgyzstan, the analysis of first births can be decomposed into two distinct processes: the entry into the first union and the transition to motherhood within a first union. Therefore, we have chosen to run separate Cox regression models for the risks of these two events. In section 6, we discuss the results of our analysis, and conclude. 


\section{Timing of the first birth in developing countries: background and hypotheses}

Fertility postponement has been studied in detail, especially for the countries of Europe and North America (see Billari et al. 2007; Sobotka 2010; Mills et al. 2011, among many others). Most studies on this topic conceptualised first birth postponement as a shift in the MAB1 to higher ages. We follow this concept in this study.

Fertility postponement was occurring in most countries of Europe between the 1960s and 1990s. In the "Western world", fertility postponement is often linked to an ideational shift towards higher levels of individual autonomy, gender equality, and a focus on "higher order needs". The changes in family behaviour associated with this shift are commonly referred to as the "Second Demographic Transition" (SDT; see Van den Kaa 1987; Lesthaeghe 2010). In addition, the sharp growth in women's tertiary education has been identified as a key driver of fertility postponement in highly developed countries (see Ní Bhrolcháin and Beaujouan 2012; see also Billari and Philipov 2004 for an earlier discussion). By contrast, in Central and Eastern Europe, fertility postponement started two or three decades later, typically in the 1990 s, when the collapse of state socialism led to serious political turbulence and economic hardship. It has been speculated that in these countries, the insecurity of young adults, rather than an SDT-style ideational change, was mainly responsible for the start of fertility postponement trends and the decrease in desired fertility (Philipov et al. 2006). Another explanation for the levels of fertility postponement that occurred in Eastern European and some Central European countries after the collapse of state socialism is that they were driven by institutional changes. For example, Ní Bhrolcháin (1993) and Speder (2005) argued that housing regulations supported early fertility under state socialism, because the birth of a child increased dwelling density, and thus increased a family's chances of being granted a larger dwelling by the authorities. Thus, the shortage of housing was a very important factor in early fertility under state socialism, but it became irrelevant as soon as the housing regulations changed in the early 1990s. Although considerable evidence has been provided that supports these economic explanations for the fertility postponement trends in Eastern Europe, value-oriented explanations for this phenomenon have also been widely discussed (Sobotka 2008).

Trends in fertility timing in developing countries continue to be much more poorly documented than trends in Europe. A systematic analysis of MAB1 trends for a large and geographically diverse group of developing countries was conducted by Bongaarts (1999) using data from the DHS and WFS surveys for the last decades of the $20^{\text {th }}$ century. His conclusion was that during that period, the MAB1 was generally increasing across the developing countries he considered. In a more recent paper, Bongaarts et al. (2017) examined the trends in first intercourse, first marriage, and first birth timing among women in 43 developing countries of Asia and North 
Africa, Latin America and the Caribbean, and sub-Saharan Africa based on DHS survey data from these countries, which were collected mainly between 1993 and 2010. The results indicated that the ages at first marriage and at first birth were increasing in most of these countries during the period under study. The authors argued that this age shift was primarily due to the expansion of girls' school participation, and that the increases in these ages would have been much more modest if the average educational level of women in the developing countries under study had not changed.

We are not aware of other recent comparative studies of MAB1 dynamics in developing countries. The failure to conduct such studies may be partly explained by a lack of satisfactory data. In addition to being considered rather unreliable, the official statistics on developing countries often contain no information on mothers' mean ages by parities, and calculating MAB1 from survey data can be difficult (Multrie et al. 2012).

Under these conditions, it has been suggested that fertility timing trends in developing countries could be approximated based on age-specific fertility rates (ASFRs), which are normally available from official statistics or from survey data. However, as ASFRs show the age distribution of births of all orders, the MAB1, which our analysis focuses on, cannot be computed from ASFRs. Nonetheless, in the descriptive part of this study, we will mainly follow ASFRs, as the agespecific fertility rate is the most readily accessible indicator of fertility timing trends. If the timing of the first birth has shifted between the age groups for which ASFRs are available (normally five-year age groups), we would expect to find that the proportions between the ASFRs of the relevant age groups have changed. Specifically, if the transition to motherhood has shifted to older ages, the ASFR of a younger age group among whom the first births were concentrated before the transition would have become smaller than the ASFR of the subsequent age group among whom the number of first births per woman had grown. If, by contrast, the timing of the transition to motherhood has shifted to earlier ages, a reverse change would be expected, with a younger ASFR becoming closer to or even overtaking the neighbouring older ASFR. It should, however, be noted that if total fertility is decreasing, it is possible that a younger ASFR proportion is growing more than an older ASFR proportion even when higher order births in the older age group are decreasing, but first birth fertility remains high and is still concentrated in the younger age group; i.e., the timing of the transition to motherhood remains stable while total fertility is decreasing. Therefore, an increase in the inputs of the ASFRs of younger age groups to total fertility do not unambiguously point to a decrease in the MAB1. Finally, when the proportions of ASFRs remain stable, it is safe to assume that the peak of first births is not moved from one age group to another. Given that in most developing countries, the mean age at first birth is below 30, it may be assumed that changes in the age at first birth that move its peak between five-year age groups affect the relative proportions of the five-year ASFRs more for the 15-19, 20-24, and 25-29 age groups than for the older age groups. Therefore, 
we will concentrate below on the relative changes in the ASFRs of these younger age groups.

Studies on individual developing countries that have investigated the ASFR trends have suggested that over the past two decades, first birth postponement has been far from universal in the developing world. Consider, for example, studies on fertility conducted at the beginning of 21st century in some MENA countries. In Algeria, the rise in the TFR from 2.2 in 2000 to 2.7 in 2008, preceded by a dramatic decline in the TFR through the 1970s to the 1990s, was mainly due to an increase in the fertility rate at ages $15-24$, which grew more than twice as much as the ASFR at ages 25-29 in that period, and thus came closer to it, but did not exceed it (OuadahBedidi and Vallin 2012). The growth of the youngest ASFRs was mainly due to a shift in the female age at first marriage to younger years, as in populations in which childbearing after marriage is considered almost obligatory, an increase in the age at first marriage normally also results in an increase in first births at those ages. A similar trend can be observed in Egypt, where a rise in total fertility from 3.0 in 2008 to 3.5 in 2014 was accompanied by a change in age patterns, with the fertility peak shifting from ages 25-29 to ages 20-24 over that period (Al Zalak and Goujon 2017). Note that since in both Algeria and Egypt total fertility was increasing with the shift in timing, there is no reason to assume that the growth in the proportion of the youngest age groups relative to the proportion of the 25-29 age group was due to a decrease in higher order births in the latter age group. For another MENA country, Jordan (Cetorelli and Leone 2012), it has been observed that the recent ASFRs trends have not pointed to a shift towards an earlier entry into motherhood, but they have not pointed in the opposite direction either. In Jordan, multidirectional changes in the TFR occurred after 2002: i.e., the TFR declined from 4.4 in 1997 to 3.6 in 2007, and then rebounded to 3.8 in 2014, under a rather stable age distribution of fertility that reached its peak at ages 25-29. In one more country with a TFR above the replacement level, Bangladesh, a fertility decline from 3.3 in 1996/97 to 2.7 in 2007 proceeded while the ASFR proportions remained stable, with fertility reaching its peak at ages 20-24 (Kamal 2010).

In the present paper, we do not study the question of how frequent the different timing trends observed in recent decades across developing countries are, or how they are related to changes in total fertility. Instead, we turn to the question of what socio-economic and cultural factors have been influencing the timing of first birth fertility in a developing country. This question has been addressed in some earlier studies on MAB1 in selected developing countries (e.g., Rindfuss et al. 1983). However, in connection with the timing phenomena of more recent years, this issue is very understudied. We consider the influence of different factors on first birth timing in Kyrgyzstan (Central Asia). There are several reasons why we focus on this country in our study. First, the preliminary evidence suggests that recent trends in reproductive behaviour in Kyrgyzstan do not involve fertility postponement. Although there are no existing ASFRs-based studies on first birth timing in Kyrgyzstan, Spoorenberg (2013) found that the TFR in the country may 
have risen in recent decades because of a fertility shift to younger ages. ${ }^{1}$ Second, the total fertility dynamics over the past 10-15 years in Kyrgyzstan have been similar to those of the developing countries without fertility postponement mentioned above, as Kyrgyzstan also experienced a decrease in total fertility without reaching the replacement level, followed by an increase in the TFR. Given the similarities in these quantum trends, it makes sense to investigate whether the timing trends were similar as well. Although the treatment of only one country cannot, of course, be the basis for cross-national generalisations, our study can give possible directions for further research on the underlying reasons for the current diversity in fertility timing observed among developing countries.

At least three groups of socio-economic and cultural parameters have been discussed in the current literature as having potential relevance for first birth timing in developing countries. The first group of parameters concerns women's education (see above on Bongaarts et al. 2017) and labour market opportunities. In the studies for individual developing countries that found evidence of fertility postponement, the role of improvements in education was often cited. For example, education was found to influence fertility postponement in Indonesia by Breierova and Duflo (2004), and both education and labour market position were shown to influence fertility postponement in Uruguay by Nathan et al. (2016). By contrast, for some countries that have not been experiencing fertility postponement in recent decades, it has been argued that high levels of fertility among the youngest age groups have been supported by social conditions under which women either had poor labour market prospects or were not motivated to take a job (Al Zalak and Goujon 2017 for Egypt).

Second, first birth fertility can be related to the degree to which gender and generation asymmetries are emphasised in family relations. It has, for example, been argued by Mason (2001), McDonald (2000) and Lerch (2013) that the empowerment of older over younger generations and of men over women within the family both of which are very common phenomena in many developing countries - may be related to higher fertility. Most of the studies on this topic have concentrated on fertility quantum rather than on timing. However, analyses of certain countryspecific data have suggested that more strict gender and generation asymmetries correspond to a younger female age at first marriage, which in developing countries is usually closely related to the age at first birth (cf. Dyson and Moore 1983 for India; see also Carmichael 2011 on the relationship between family organisation and the age at first marriage in a sample of less developed countries). There are several reasons to expect that women and younger generations having subordinate positions in the family can influence fertility timing. First, the empowerment of elders can put social pressure on young women to follow the fertility patterns of preceding generations, including in terms of timing (see Bongaarts and Watkins 1996 on the

\footnotetext{
Spoorenberg (2013) pointed to the possibility of both a lowering of the MAB1 and a shortening of interbirth spacing. The procedure he used does not allow us to distinguish between the two phenomena.
} 
role of social pressure in fertility behaviour). Second, in some societies with strict gender asymmetries, childbearing is the main way for a woman to achieve a high social position (Salway 2007). Thus, in such situations, a woman may be motivated to become a mother as soon as possible.

Third, ethnicity or religious affiliation can play a significant role in first birth timing. This expectation is based on studies that found evidence of first birth timing differences between ethnic or religious groups in developing countries. For example, Fazle Rabbi and Imrul Kabir (2013) argued that first birth timing differs significantly between Muslim and non-Muslim women in Bangladesh; see also Ngalinda (1998) for a similar conclusion in Tanzania. Rindfuss et al. (1983) found that both religion and ethnicity played a role in the mother's age at first birth in developing countries of South-East Asia. Since these differences remained significant when socio-economic parameters were controlled for, it can be argued that religion and ethnicity may influence the dynamics of first birth timing.

Against this background, in the present paper, we study the following hypotheses on the timing of the first birth in developing countries.

Hypothesis 1. A woman's age at first birth is positively related to her educational and labour market opportunities.

Hypothesis 2. A woman's age at first birth is negatively related to parameters that point to strict gender and generation asymmetries in family relations.

Hypothesis 3. In a multi-confessional and multi-ethnic country, the age at first birth can differ significantly among women with different ethnicities or religious affiliations, even after controlling for key socio-economic parameters.

\section{Kyrgyzstan: key facts on population and fertility}

Like most other post-Soviet countries, Kyrgyzstan, which had a total population of 6.3 million in 2018, experienced a dramatic decrease in fertility after the collapse of the Soviet Union (1991), which was followed by an increase in fertility in the 2000s (see Figure 1 for a comparison of the TFR dynamics of Kyrgyzstan with the trends of some of its neighbours). The decrease in the 1990s can be regarded as a final stage of the decline in fertility that started as early as in the 1970s following a peak reached in the 1960s. This decline was typical for countries undergoing the First Demographic Transition, but it did not reach the replacement level (TFR = 2.1), which marks the final stage of that transition. The current TFR in Kyrgyzstan is higher than that of its northern neighbour Kazakhstan, but it is lower than that of Tajikistan, the fertility "champion" in Central Asia.

Official data on fertility timing in Kyrgyzstan are available from the yearbooks that can be accessed at the official site of the National Statistical Committee of the 
Figure 1:

Period TFR in Kyrgyzstan, Kazakhstan, and Tajikistan, 1960-2017

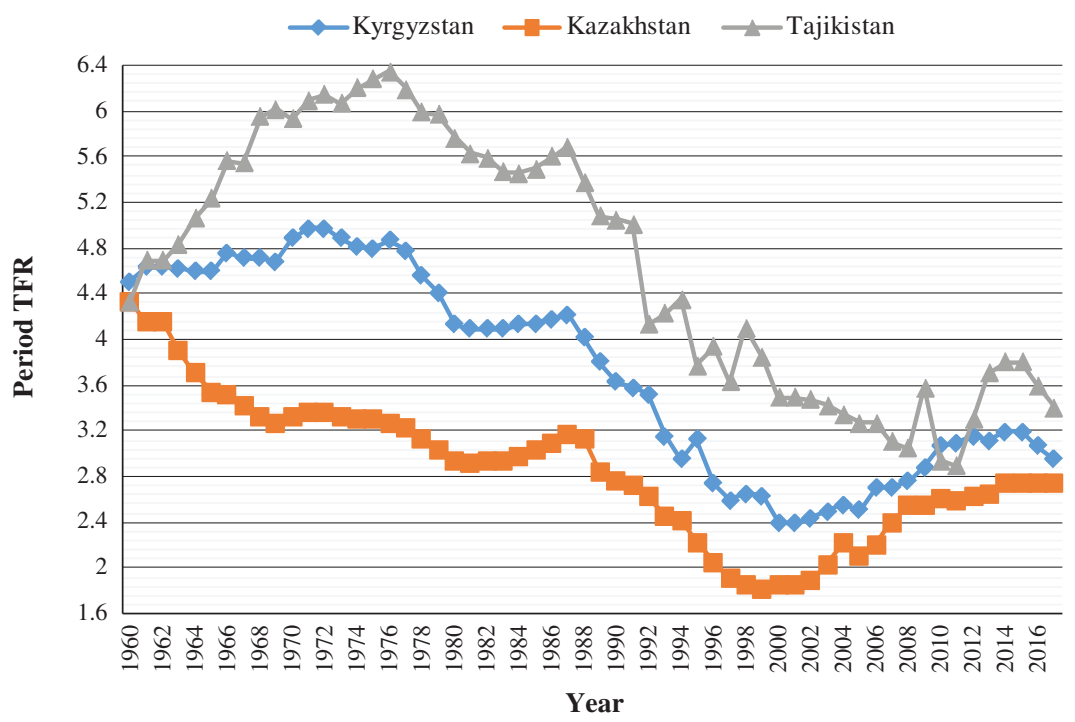

Source: Based on data available at: http://www.demoscope.ru/weekly/ssp/sng_-tfr.php

Kyrgyz Republic. ${ }^{2}$ According to this source, the MAB1 was stable in Kyrgyzstan in the 2010s, averaging 23.0 years in 2012-2016 and 22.9 years for both 2017 and 2018. The ASFRs based on census data demonstrate that the proportions of age groups in total fertility were also quite stable between 1989 and 2009, with the ASFR remaining the highest for the 20-24 age group (Denisenko et al. 2012). In Figure 2, the ASFRs based on the data from the major sample surveys carried out in Kyrgyzstan between 2000 and 2015 are plotted (see the next section for some remarks regarding the accuracy of survey data on Kyrgyzstan). Again, it can be seen that the age distribution of fertility remained quite stable during this period, with no shift in the fertility peak from the 20-24 age group to the older age groups. (Note that since total fertility was growing for most of the time period between the surveys, it is unlikely that the finding that the proportion of fertility was highest in the 20-24 age group was due to a decrease in fertility in the older groups because of a decrease in higher order births).

The share of fertility that occurred outside of registered marriage amounted to $21.5 \%$ in 2018 (it varied between $16.1 \%$ and $29.4 \%$ from region to region). However, as the survey data show very low proportions of births outside of actual unions, the

2 http://stat.kg/en/publications/demograficheskij-ezhegodnik-kyrgyzskoj-respubliki/ 
Figure 2:

Age-specific fertility rates (ASFR) in Kyrgyzstan, selected surveys 2005-2014 (with 95\% confidence intervals)

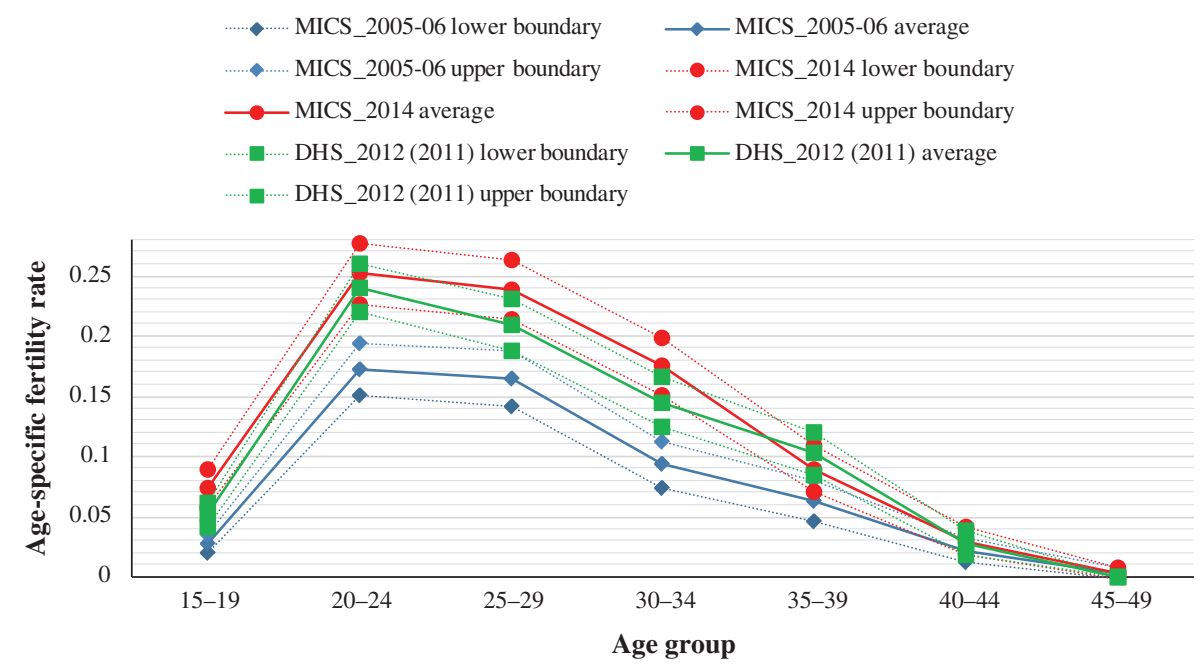

high levels of fertility outside of registered marriage may be explained by a lack of civil registration of unions that had been confirmed under religious law.

Kyrgyzstan is a multi-ethnic country. Its main ethnic groups are Kyrgyz (making up $71 \%$ of the population according to the 2009 census, and $73.5 \%$ of the population according to the administrative sources for 2018), Uzbeks (14.3\%/14.7\%), and Russians (7.8\%/5.5\%). Most Kyrgyz and Uzbeks are Muslims, and most Russians are Orthodox Christians. Like the other former Soviet Republics of Central Asia, Kyrgyzstan experienced a sizable out-migration after 1991, with ethnic Russians being especially likely to leave the country (Tishkov 1994). The other ethnic groups present in Kyrgyzstan are heavily involved in temporary labour migration, mainly to Russia. A migration survey conducted in Kyrgyzstan in 2018 reported that more than 700,000 Kyrgyzstan citizens were registered in other countries, including 640,000 in Russia (State migration service under the Kyrgyzstan government, 2019). Russian statistics for 2016 have reported that the country was hosting 360,000 400,000 labour migrants from Kyrgyzstan (10\% of all labour migrants coming to Russia). It is noteworthy that the proportion of migrants from Kyrgyzstan to Russia who are women has been about $40 \%$ in recent years, which is higher than it has been among most of other migration flows targeting Central and Eastern Europe (FIDH 2016).

Kyrgyz and Uzbeks occupy different areas of the country, with Uzbeks mainly concentrated in the south. Although a revival of Islamic religious practices has been a general trend in Kyrgyzstan and in other post-Soviet countries of Central 
Asia since the collapse of the Soviet Union, it has been observed that among local Uzbeks, the social role of Islam is larger, and its forms are more "radical" according to certain definitions (cf. Tromble 2014). The level of urbanisation is highest among Russians, a majority of whom have been living in urban areas since the Soviet era. The educational levels in Kyrgyzstan have remained rather stable in the post-Soviet period according to census data, as the proportion of people with high (tertiary) education among those older than age 15 was $11.0 \%$ in $1989,10.5 \%$ in 1999 , and $12.4 \%$ in 2009 (Census data available from http://www.demoscope.ru/weekly/ ssp/sng_chi_89.php). Currently, according to the National Statistics Office, tertiary education has been declining somewhat, mainly due to the liquidation of universities outside of the capital of Bishkek. The number of university students in the country's population decreased from 43,000 in the 2012/2013 academic year to 30,000 in the 2016/2017 academic year.

When we look at the gender and generational relations of post-Soviet Kyrgyzstan, we see that many traditional asymmetries have been preserved that empower men over women and older over younger generations. In part, these asymmetries were strengthened by post-Soviet "nation-building" propaganda calling for a return to patriarchal family relations (Kandiyoti 2007). Ismailbekova (2016) has shown that families remain strictly patrilocal, with housekeeping obligations being mainly imposed on wives. Generation asymmetries are manifested in, for example, the subordination of young wives to the parents and elder relatives of their husbands. Although the traditional family norms are currently being challenged by the intensive labour migration of the male population, which makes the role of women more decisive in many family questions (Ismailbekova 2014), these norms currently remain dominant in the family relations of the native peoples of Kyrgyzstan.

Several studies have addressed fertility trends in post-Soviet Kyrgyzstan. Spoorenberg (2015), considered possible explanations for the recent increase in the TFR in the countries of Central Asia, and argued that timing changes could be among them. He found that in Kyrgyzstan, the growth in the observed TFR was accompanied by downward movement of the tempo-adjusted TFR (Bongaarts and Feeney 1998) in the first half of the 2000s. This pattern signals that a tempo shift towards younger fertility conditioned the TFR growth. In the second half of the 2000s, the observed and the adjusted TFRs were increasing in parallel in Kyrgyzstan, which allows us to conclude that at that time, quantum growth contributed to the growth of the observed TFR together with the shift to earlier timing. Importantly for the purposes of our study, the comparison of the observed and the tempo-adjusted TFR provides evidence that fertility postponement did not occur in Kyrgyzstan in the 2000s, because in the postponement situation, the adjusted TFR would be expected to show dynamics that are more positive than those found in Kyrgyzstan. Inputs of different parities to the fertility increase in Kyrgyzstan were considered by Spoorenberg (2017), who concluded that the TFR growth in the 2000s was mainly due to increases in the first and second parities that took place in all ethnic groups.

The impact of ethnicity on fertility in Kyrgyzstan between 1990 and 2005 was studied by Nedoluzhko and Andersson (2007). They found that the risk of entry 
into first parenthood was lower among Russians living in Kyrgyzstan (whom they categorised as "Europeans" together with other peoples of European origin, such as Ukrainians) than among native-speaking representatives of Turkic ethnicity (Kyrgyz, Uzbeks), but also that the risk was still significantly lower among Russianspeaking representatives of Turkic peoples than among Europeans. In a comparison of fertility trends among the major ethnic groups of Kyrgyzstan and Kazakhstan between the middle of the 1990s and the middle of the 2000s, Agadjanian et al. (2013) showed that how the fertility levels of the ethnic groups reacted to the economic growth of the 2000s had no direct correspondence to their rankings in terms of absolute fertility levels, as only the fertility levels of Russians - the least fertile ethnic group - grew much more in the mid-2000s than in the mid-1990s. The authors explained this finding by noting the lower base of fertility of Russians before the start of the period of economic growth in both countries, and by citing selectivity effects, whereby Russians who did not leave Central Asia probably were better adapted to local realities than their co-ethnics who preferred to leave the country.

In the countries of Central Asia, ethnic and cultural differences have been reported not only for fertility, but for union formation patterns. Thus, Agadjanian and Dommaraju (2011) argued that in Kyrgyzstan, the probability of entering an unregistered cohabitation is highest among European women, lower for Russified Kyrgyz women, and still lower for non-Russified Kyrgyz women; whereas the probabilities of entering a registered marriage are in the reverse order for the three groups of women. This implies that the more pronounced "traditionalism" in couple formation is related not just to the ethnicity, but to the cultural background of women (this is even more the case for men, among whom the gap in the probability of entering cohabitation is even greater between Russified and nonRussified Kyrgyz than between Europeans and Kyrgyz). It should be noted that the label of cohabitation (unregistered marriage), which is used in both census and survey results, can conceal very diverse phenomena in Kyrgyzstan, ranging from "European-style" cohabitation to Islamic marriage without state registration. According to Denisenko et al. (2012), the growth in marriage rates in Kyrgyzstan between 1999 and 2009 left the proportion of unregistered marriages at a stable level of about $8 \%$. Among ethnic Russians, most of whom are not Muslims, and among whom religious sources of unregistered marriage are less probable, that proportion was nearly twice as high as it was among Kyrgyz. A very high propensity for marriage among pregnant women in Kyrgyzstan was reported by Nedoluzhko and Agadjanian (2010), which suggests that the acceptance of out-of-union births in the country is low.

The data considered in this section may provide evidence of the stability of fertility timing in light of our hypotheses in Section 1. Specifically, the finding that educational levels in the country are stable would be in line with the lack of fertility postponement shown by official statistics (Hypothesis 1). The differences in religious affiliation found between Russians on the one hand and Kyrgyz and Uzbeks on the other indicate that the timing trends can differ between different 
ethnicities. Timing differences between Uzbeks and Kyrgyz can also be expected because they represent different ethnicities, and possibly because of differences in their religious and cultural practices.

\section{Data}

Two representative surveys were used in our analysis: the Multiple Indicators Cluster Surveys conducted in 2014 (MICS2014) and the Demography and Health Survey conducted in 2012 (DHS2012). Both surveys covered a national-level representative sample of women aged 15-49. The MICS2014, conducted between April and June 2014, covered 6854 women. The DHS was conducted between August and December 2012, and had 8208 women in its individualized record set. According to official reports on these surveys, the response rate for women was $96 \%$ in the MICS2014 and 97\% in the DHS2012.

Here, we briefly consider the limitations of the data provided by these surveys. First, the survey samples did not include women who were engaged in temporary labour migration. Thus, births that took place in the country to women who had undertaken out-migration before the time of the survey are outside of the scope of the survey data, which could distort both period fertility estimates for past years and age-specific cohort fertility estimates. At the same time, migrants are often already selected for lower fertility in their home country. This is especially likely for those engaged in labour migration, which is typically undertaken by more educated and less family-oriented women. For this reason, the under-registration of the fertility of current migrants in past years is likely to result in a bias towards the fertility indicators having a higher meaning. Note, however, that this bias is not expected to be more pronounced at younger than at older ages. Indeed, the younger an age point is, the more probable it is that future labour migrants were still in the home country by that age at the time of the survey, and, therefore, the less probable it is that the survey fertility indicators were biased because of the under-registration of the in-the-country fertility of future migrants at that age. Thus, crucially for our purposes, we have no reason to expect that the possible under-registration of fertility of future migrants causes a more serious overestimation of fertility at younger than at older ages. ${ }^{3}$

Another limitation is related to the possible under-representation of childless women. It is generally expected that in developing countries, unmarried and childless women may be under-represented in a sample because of the cultural inappropriateness of being unmarried or childless after reaching a certain age (see, e.g., Hull and Hartanto 2009). Note that Spoorenberg (2017) has argued that

\footnotetext{
3 Note that the results of the Russian census for 2010 appear to confirm the suggestion that Kyrgyz migrants were selected for lower fertility, as they signal that the completed fertility of real cohorts of Kyrgyz women living in Russia at the time of the census was much lower than that of Kyrgyz living in Kyrgyzstan (not shown here).
} 
childlessness is under-represented to a greater extent in the DHS2012 than in the vital statistics for Kyrgyzstan. When studying first birth timing, relying on incorrect estimates of proportions of childlessness can, of course, result in distortions. Our only option for estimating the under-representation of childless women in the sample surveys was to compare their results with those of other sources for which the omission of this category of women is less likely. We have compared the estimates of the proportions of women who have at least one child at different ages between 15 and 40 from the Kyrgyzstan census for 2009 with those from the DHS2012 and the MICS2014. For the surveys, it was possible to calculate this proportion retrospectively for 2009 , as they contain information on the date of the first birth for all of the fertile women in their samples. Indeed, compared to the census, both the MICS and the DHS have reported higher proportions of women having at least one child for some age groups (the results of the comparison are not shown here for reasons of space). It is, however, clear that in both surveys, this underestimation mainly occurs for the 25-29 and older age groups. Given that both surveys show that the peak of first birth fertility was below age 25 , we do not expect that this overestimation will seriously distort our analysis of first birth timing based on the survey data.

\section{The analysis}

In our first analytical step, we compared the cumulative probability of remaining childless by age among neighbouring birth cohorts using survey data from both the DHS2012 and the MICS2014. This comparison allowed us to see whether the cumulative probability of having the first child at different ages changed from one five-year birth cohort to another, starting from the cohort born in 1965-1969 and ending with the cohort born in 1995-1998. ${ }^{4}$ We concentrated on a comparison of event risks across cohorts rather than across periods because the cohorts included in the study differed considerably in terms of the social conditions they experienced at the start of their reproductive period. Members of the oldest cohort underwent socialisation and spent a portion of their reproductive period in the Soviet era, while subsequent cohorts started their reproductive period in the post-Soviet turmoil, and the youngest cohorts started their reproductive period in the 2010s. Thus, the cohort analysis allowed us to look at how changes in social experiences influenced the first birth decisions of respondents.

Figures 3 and 4 plot the cumulative probabilities of childlessness at different ages by birth cohort according to data from the DHS2012 and the MICS2014. They do not show a considerable expansion of childlessness towards older ages in the younger cohorts. The lack of such an expansion was confirmed by statistic tests.

\footnotetext{
4 The youngest cohort included women with only four years of birth, as those born in 1999 were absent from the DHS2012 sample, and their proportion in the MICS2014 sample was very low.
} 
Figure 3:

Cumulative monthly probability of childlessness from age 15 according to the MICS2014 (women born 1965-1998)

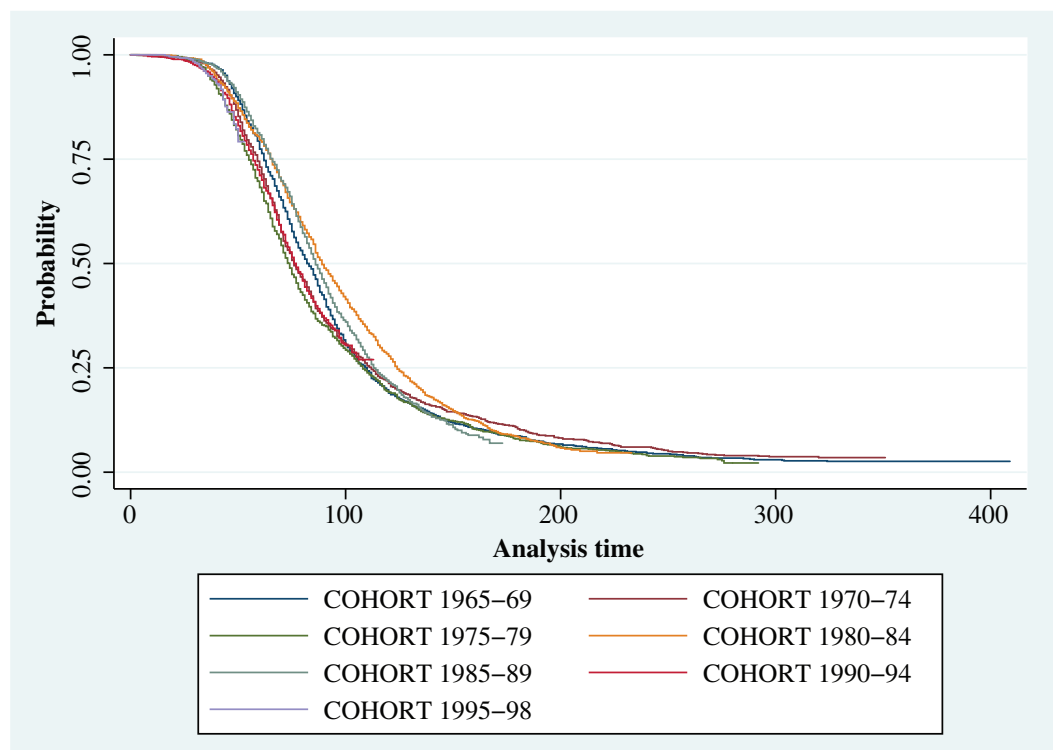

Table A.1 of the Appendix sums up the statistic tests that measured differences in the cumulative probability of remaining childless between neighbouring birth cohorts according to the DHS2012 and the MICS2014; i.e., these tests indicated whether the differences between the cohorts shown in Figures 3 and 4 were statistically robust. Standard tests for a comparison of Kaplan-Meier estimates were used. For each cohort, the cumulative probability of remaining childless was estimated for each month starting from the age of exactly 15 years. There were two cohorts for whom the data from both surveys signalled a significant difference between each cohort and the preceding cohort: these were the cohorts born in 1980-84 and in 1990-94. For the 1980-84 cohort, a postponement of the first birth compared to the timing of the first birth in the 1975-79 birth cohort could be observed (a subsequent recuperation occurred for the 1985-89 cohort according to the MICS2014, but not according to the DHS2012). For the cohort born in 1990-94, the cumulative probability of remaining childless was lower than that for the cohort born in 198589 at all ages reached by both cohorts before the time of the survey. Thus, there was only one cohort for whom the Kaplan-Meier analysis showed a postponement of the first birth compared to the timing of the first birth in the preceding cohort, and there was one more cohort for whom the analysis found that the timing of the first birth was earlier than it was in the preceding cohort. Of course, these findings do not allow us to assume that fertility postponement from older birth cohorts to younger cohorts 
Figure 4:

Cumulative monthly probability of childlessness from age 15 according to the DHS2012 (women born 1965-1998)

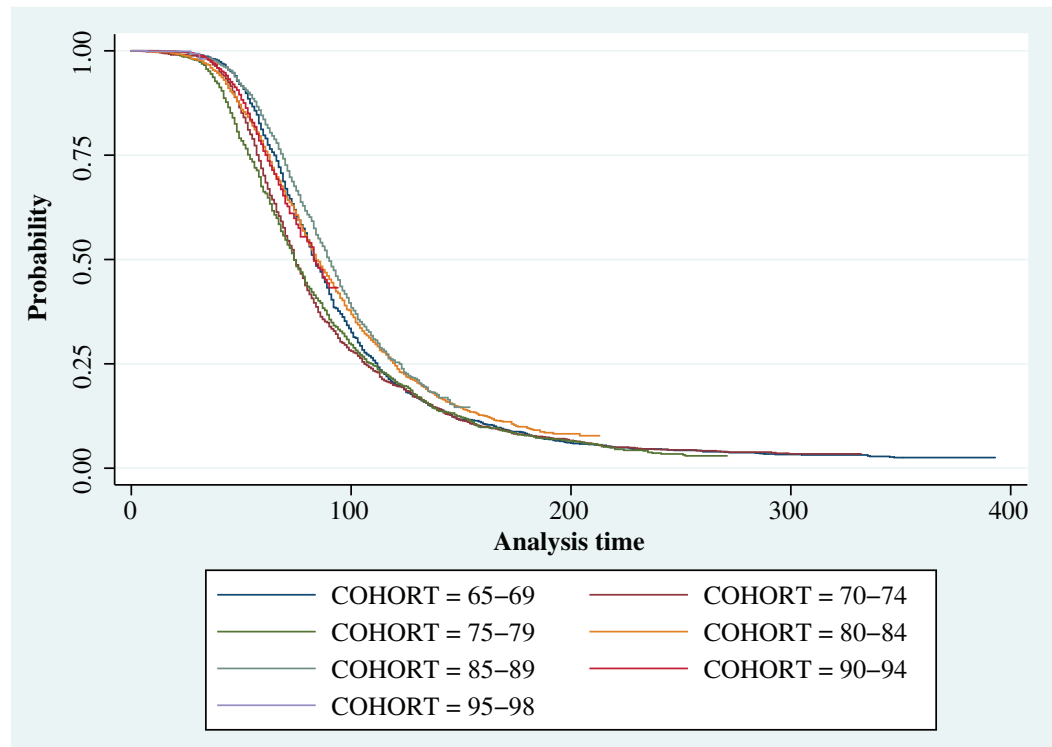

was the dominant trend. Note also that the similarity of the estimations based on the two surveys makes this result more robust.

For a more accurate statistical account of the timing trends, Cox regressions were built for the sample from the MICS2014. We have chosen the MICS2014 data for the regression analysis because they are the most up-to-date survey data that are available to us. Two sets of models were run: one for proportional risks of first union starting from the age of 15 years zero months, and one for the proportional risks of first birth starting from the month of the first union. Studying the risks of first birth only among women who had been in a partnership made sense for Kyrgyzstan, as births outside of a partnership are still very infrequent in that country. In the MICS2014 sample, there were only two women who reported having given birth to a child, but having never been in a partnership. Only $1.1 \%$ of women who had a child provided a first birth date that preceded the date of the start of their first partnership (these respondents were not included in the analysis of first birth risks, but given that they made up only a small proportion of the sample, their exclusion was unlikely to distort the results). We identified a number of reasons to follow the somewhat nonstandard path of running the two separate sets of models instead of one set of models for the first birth, which could have marital status as a time-varying parameter. First, given that out-of-union fertility is very rare in this context, considering a woman's first birth risks for the period before she entered her first union looked superfluous. 
Second, the MICS data did not allow us to assign the marital status to each time period in the life course of each woman in the sample because even though the data contained information on the dates of entry into the first union, it did not specify the dates of divorces or of the deaths of partners. Therefore, the assignment of the timevarying parameter of marital status to divorced/separated women and to widows could produce inaccurate estimates. Finally, the two sets of models allowed us to disentangle the effects of the transition to the first union and to the first birth in a union on first birth fertility, which would have been impossible if only the risks of first birth starting from age 15 were studied.

Importantly, the MICS2014 data supplied information on the age at first union rather than on the age at marriage. This represented a limitation for our analysis, as we were unable to determine whether a child was born in a registered marriage. However, as we mentioned above, unregistered unions became more common in the country in the post-Soviet period. Therefore, it is more appropriate to assume that the start of a first union, rather than the registration of a marriage, was the main precondition for a first birth. Another limitation was that, as we noted above, the MICS data did not allow us to determine how much time a woman spent in her first union if she was divorced/separated or became a widow. However, according to the MICS2014, union dissolution was a relatively infrequent phenomenon, as only 7.5\% of women who reported ever having been in a union described themselves divorced or separated at the time of the survey, and only another $5.7 \%$ stated that their current union was not their first union.

A variable indicating the birth cohort was included in each model. As in the Kaplan-Meier estimates above, we used five-year birth cohorts starting from 196569. For each cohort, the relative hazard ratios compared to those of the reference birth cohort of 1965-69 are considered. A number of socio-economic and cultural parameters are also added to the models. Thus, in all of the models that have covariates in addition to the cohort variable, parameters of urban/rural residence and educational level are included. The education parameter was dichotomic, and distinguished between higher educational levels (studying at a university or an institute, with or without having completed a degree) and lower educational levels. To measure the impact of ethnicity, the parameter of the mother tongue of the household head was included in the models. In the MICS2014 database, this is the only proxy for ethnicity. Recall that the mother tongue, rather than the selfreported ethnic identity, was shown to be significant for marriage behaviour in existing studies of post-Soviet Kyrgyzstan (see Section 3).

The MICS2014 survey offered a rather limited set of parameters that can be treated as indicators of gender asymmetries. We used the dichotomic parameter showing whether a woman considered a husband beating his wife acceptable (we assigned a positive meaning to this parameter when the respondent said that wife beating was acceptable under at least one condition in a list of conditions proposed in the survey questionnaire). We assumed that if a woman accepted domestic violence, this acceptance was probably imposed on her by the norms and behavioural 
standards she has encountered either among her relatives or in her husband's family. In the models for the transition to the first child, we additionally included the age gap between the woman and her partner. A larger age gap between a woman and her partner was often associated with more strict gender asymmetries in a family (Casterline et al. 1986). As a socio-economic variable, we also used the level of wealth (a quantile wealth index; hazard ratios for women of different quintiles relative to the lowest quintile are considered). Finally, the frequency of internet access was included as a parameter in the models. Generally speaking, internet access was expanding in Kyrgyzstan in the 2000s and the 2010s, with the overall penetration rate reaching $78.6 \%$ in 2018 , according to the State Communication Agency. At the same time, the extent to which women in Kyrgyzstan have access to the internet is likely to reflect certain cultural differences. It may, for example, be noted that women of different ethnic groups have different levels of internet access (see Table 1), with Kyrgyz women having greater access than Uzbeks, and both ethnicities having less access than Russians. 5

The education, urban/rural residence, employment, and wealth index parameters were time-fixed in our models because the MICS data did not allow us to have these parameters varying across a woman's life course. Assigning the educational level a woman had reached by the time of the survey to all months of her life course that were included in the analysis seemed justifiable because women normally start higher (tertiary) education at ages 18-19 in Kyrgyzstan, which means that only the very early stages of a woman's reproductive period would be unaffected by the decision to enrol in higher education (moreover, it was highly probable that a woman would spend the years between turning age 15 and entering university preparing for admission exams, which would also influence her marriage and fertility behaviour at that time). Treating the level of wealth as a time-fixed variable was justified by its rather undetailed, quintile-based scale; and given the relatively low levels of wealth mobility in Kyrgyzstan, it was improbable that a woman would radically change her position on the scale during her life course (movements between neighbouring quintiles were not expected to produce serious distortions).

Table 1 contains descriptive results on the parameters included in our analysis for women born between 1965 and 1998, for the whole sample, and for the three major ethnicities.

Table 2 shows Cox regressions for entering the first union, and Table 3 shows Cox regressions for the transition from the first union to having one child for the whole sample. In both tables, a regression is included with the birth cohort as the only variable, and then a series of regressions are included to which the other covariates

\footnotetext{
5 Note that these differences between ethnicities cannot be accounted for by the proportions of urban women among them (based on the assumption that internet access is better in urban areas), because the proportion of the population living in urban areas is higher among the Uzbeks than among Kyrgyz, according to Kyrgyzstan National Statistics Office (Ezhegodnik 2017), whereas internet access is greater among the latter than among the former.
} 
Table 1:

Distribution of some parameters in the MICS2014 (total and by ethnic groups)

\begin{tabular}{lcccc}
\hline & All & Kyrgyz & Uzbeks & Russians \\
\hline Urban,\% & 38.5 & 35.2 & 49.1 & 62.2 \\
Higher education, \% & 25.4 & 28.7 & 8.1 & 38.1 \\
Accepting domestic violence, \% & 38.0 & 37.7 & 46.6 & 12.9 \\
Age gap with husband, mean & 4.57 & 4.53 & 4.85 & 4.08 \\
Wealth quintiles, \% & & & \\
$\quad$ Poorest & 21.8 & 24.2 & 18.6 & 1.4 \\
$\quad$ Second & 19.0 & 20.9 & 16.3 & 1.9 \\
$\quad$ Middle & 19.4 & 17.8 & 31.5 & 7.4 \\
$\quad$ Fourth & 20.3 & 17.3 & 29.5 & 30.1 \\
$\quad$ Richest & 19.5 & 19.8 & 4.1 & 59.2 \\
Having a job (among those born & 10.0 & 9.4 & 6.1 & 28.7 \\
in 1989-1998), \% & & & & \\
Access to internet (among those born in $1989-1998)$ & \\
$\quad$ No & 1.5 & 1.3 & 3.2 & 1.1 \\
$\quad$ Less than once a week & 13.0 & 11.7 & 28.5 & 2.2 \\
$\quad$ At least once a week & 23.5 & 23.5 & 31.5 & 10.9 \\
$\quad$ Almost every day & 62.0 & 63.5 & 36.7 & 85.9 \\
$N \quad 6684$ & 5029 & 1070 & 365 \\
\hline
\end{tabular}

are successively added. The following asymmetries between women of different birth years can be seen. First, women of the 1980-84 birth years had a significantly lower propensity for both entering a first union and giving birth to a first child than women of other birth years. The findings for entering the first union hold for both the regression with the cohort as the only variable and the models with the addition of covariates. For the first birth, this effect was observed only in the models to which covariates were added. Second, the cohorts born in the 1990s were shown to have significantly higher risks of both events. This was especially clear for the transition to motherhood, for which both the 1990-94 and 1995-98 birth cohorts were found to have significantly higher risks than women of older generations in the regressions both with and without the covariates added (note, however, that for the 1995-98 birth cohorts, the results on the transition to motherhood could be spurious, as the subgroup of that cohort who were already in partnership by the time of the survey i.e., before age 20 - was highly selective). For the transition to the first union, the risks were shown to be significantly higher for the 1990-94 birth cohort only, and only in the regressions with the covariates added, and the risk ratios with the oldest generation were found to be smaller. Nevertheless, the analysis confirmed that none 
Table 2:

Risks of transitioning to a first union by age (Cox regression, starting at age 15)

\begin{tabular}{|c|c|c|c|c|c|}
\hline & (1) & (2) & (3) & (4) & (5) \\
\hline \multicolumn{6}{|l|}{ Birth cohort } \\
\hline 1965-69 & 1 & 1 & 1 & 1 & 1 \\
\hline $1970-74$ & 0.985 & 1.006 & 1.020 & 1.019 & 1.017 \\
\hline $1975-79$ & 1.082 & $1.099^{*}$ & $1.097^{*}$ & 1.086 & 1.082 \\
\hline $1980-84$ & $0.844^{* *}$ & $0.885^{* *}$ & $0.876^{* * *}$ & $0.871^{* * *}$ & $0.868^{* * *}$ \\
\hline $1985-89$ & $0.912^{*}$ & 0.994 & 0.983 & 0.978 & 0.974 \\
\hline 1990-94 & 1.073 & $1.182^{* *}$ & $1.177^{* * *}$ & $1.186^{* * *}$ & $1.183^{* * *}$ \\
\hline 1995-98 & 0.963 & 0.973 & 0.964 & 0.984 & 0.983 \\
\hline \multicolumn{6}{|l|}{ Area } \\
\hline Urban & & 1 & 1 & 1 & 1 \\
\hline Rural & & $1.235^{* * *}$ & $1.237^{* * *}$ & $1.233^{* * *}$ & $1.177^{* * *}$ \\
\hline \multicolumn{6}{|l|}{ Education } \\
\hline No higher ec & ducation & 1 & 1 & 1 & 1 \\
\hline Higher educ & cation & $0.558^{* * *}$ & $0.580^{* * *}$ & $0.590^{* * *}$ & $0.600^{* * *}$ \\
\hline \multicolumn{6}{|l|}{ Ethnicity } \\
\hline Kyrgyz & & & 1 & 1 & 1 \\
\hline Russian & & & $0.792^{* * *}$ & $0.824^{* * *}$ & $0.844^{* * *}$ \\
\hline Uzbek & & & $1.213^{* * *}$ & $1.201^{* * *}$ & $1.178^{* * *}$ \\
\hline \multicolumn{6}{|c|}{ Accepts domestic violence } \\
\hline No & & & & 1 & 1 \\
\hline Yes & & & & $1.176^{* * *}$ & $1.164^{* * *}$ \\
\hline \multicolumn{6}{|l|}{ Wealth index } \\
\hline Poorest & & & & & 1 \\
\hline Second & & & & & 1.014 \\
\hline Middle & & & & & 0.985 \\
\hline Fourth & & & & & 1.031 \\
\hline Richest & & & & & $0.881^{* *}$ \\
\hline $\begin{array}{l}\text { Chi-square } \\
\text { significance }\end{array}$ & $p<000.1$ & $p<000.1$ & $p<000.1$ & $p<000.1$ & $p<000.1$ \\
\hline $\begin{array}{l}-2 \log \\
\quad \text { Likelihood }\end{array}$ & 80047.708 & 77377.740 & 77336.277 & 77305.410 & 77295.171 \\
\hline$N$ & 6304 & 6304 & 6304 & 6304 & 6304 \\
\hline
\end{tabular}


Table 3:

Risks of transitioning to a first birth in a union (Cox regression, by the time since the first union)

\begin{tabular}{|c|c|c|c|c|c|c|}
\hline & (1) & (2) & (3) & (4) & (5) & (6) \\
\hline \multicolumn{7}{|l|}{ Birth cohort } \\
\hline $1965-69$ & 1 & 1 & 1 & 1 & 1 & 1 \\
\hline $1970-74$ & 1.055 & 0.995 & 1.001 & 0.997 & 0.985 & 0.985 \\
\hline $1975-79$ & $1.139^{* *}$ & 1.075 & 1.079 & 1.071 & 1.057 & 1.055 \\
\hline $1980-84$ & 0.934 & $0.901^{* *}$ & $0.894^{* *}$ & $0.891^{* *}$ & $0.874^{* *}$ & $0.878^{* *}$ \\
\hline $1985-89$ & 1.057 & $1.097^{*}$ & 1.087 & 1.083 & 1.062 & 1.064 \\
\hline 1990-94 & $1.806^{* * *}$ & $2.053^{* * *}$ & $2.038^{* * *}$ & $2.035^{* * *}$ & $2.002^{* * *}$ & $2.002^{* * *}$ \\
\hline 1995-98 & $6.239^{* * *}$ & $7.344^{* * *}$ & $7.236^{* * *}$ & $7.250^{* * *}$ & $6.998^{* * *}$ & $6.998^{* * *}$ \\
\hline \multicolumn{7}{|l|}{ Area } \\
\hline Urban & & 1 & 1 & 1 & 1 & 1 \\
\hline Rural & & $1.100^{* * *}$ & $1.116^{* * *}$ & $1.117^{* * *}$ & $1.125^{* * *}$ & $1.122^{* * *}$ \\
\hline \multicolumn{7}{|l|}{ Education } \\
\hline No higher education & & 1 & 1 & 1 & 1 & 1 \\
\hline Higher education & & $0.606^{* * *}$ & $0.626^{* * *}$ & $0.632^{* * *}$ & $0.639^{* * *}$ & $0.640^{* * *}$ \\
\hline \multicolumn{7}{|l|}{ Ethnicity } \\
\hline Kyrgyz & & & 1 & 1 & 1 & 1 \\
\hline Russian & & & 0.950 & 0.972 & 0.967 & 0.963 \\
\hline Uzbek & & & $1.183^{* * *}$ & $1.175^{* * *}$ & $1.174^{* * *}$ & $1.156^{* * *}$ \\
\hline \multicolumn{7}{|c|}{ Accepts domestic violence } \\
\hline No & & & & 1 & 1 & 1 \\
\hline yes & & & & $1.097^{* * *}$ & $1.093^{* * *}$ & $1.094^{* * *}$ \\
\hline Age gap with husband & & & & & $1.009^{* * *}$ & $1.009^{* * *}$ \\
\hline \multicolumn{7}{|l|}{ Wealth index } \\
\hline Poorest & & & & & & 1 \\
\hline Second & & & & & & 0.998 \\
\hline Middle & & & & & & 1.009 \\
\hline Fourth & & & & & & $1.101^{*}$ \\
\hline Richest & & & & & & 0.958 \\
\hline $\begin{array}{l}\text { Chi-square } \\
\text { significance }\end{array}$ & $p<0.001$ & $p<0.001$ & $p<0.001$ & $p<0.001$ & $p<0.001$ & $p<0.001$ \\
\hline $\begin{array}{l}-2 \log \\
\quad \text { Likelihood }\end{array}$ & $67394.563^{* * *}$ & 67041.169 & 67023.350 & 67014.196 & 66990.649 & 66982.233 \\
\hline$N$ & 4555 & 4555 & 4555 & 4555 & 4555 & 4555 \\
\hline
\end{tabular}

of the models showed a trend towards postponement of the first union or of the first birth in the younger cohorts, and that most of the models indicated that the direction of change went in the opposite direction.

Both Tables 2 and 3 show that adding the socio-economic and cultural variables made the analysis more accurate (this was obvious due to the higher $-2 \mathrm{Log}$ Likelihood statistics in the regressions to which the variables were added). These 
findings justified considering models to which the variables were added, although the Chi-square indicator was significant even for the regressions that only included the cohort variable.

Most of the additional covariates had a significant effect on the propensity for at least one of the events to occur. Ethnic differences were also detected by the analysis, as both of the risks under study were found to be significantly higher among Uzbeks than among Kyrgyz. Moreover, Russians were found to have significantly lower risks of entering a first union than Kyrgyz and Uzbeks. However, for the transition to motherhood, the differences between Russians and Kyrgyz were shown to be insignificant. Both the first union and the first birth risks were found to be lower among women with higher education and among urban women. Among the indicators of family relations, acceptance of domestic violence was shown to be significantly related to higher risks of both entering a first union and having a first birth. A larger age gap between a woman and her husband was also found to increase the risk of transitioning to a first birth, although the size of the risk ratio was very small. Finally, the propensity for entering a first union was revealed to be significantly lower among women of the richest wealth quintile. The significance of the impact of wealth on the transition to the first birth was, however, found to be low.

We also ran separate models for women who were born between 1989 and 1998. We did this because the MICS data contained some additional parameters for those women which were of interest to us given our hypotheses: namely, having a job at the time of the survey and the frequency of internet use. The latter parameter could be important in light of our hypothesis that more strict gender and generational relations in a family were linked to the earlier timing of demographic events. We assumed that if a woman was able to use the internet frequently, this was an indication that her information sources and her ability to communicate were not being tightly controlled by family members (cf. Guilamo-Ramos et al. 2015).

Models for the transition to the first birth showed almost no significant effects for such women, probably because the numbers of women who were in a partnership among these cohorts were low, and are not shown here. Models for the transition to the first union are shown in Table 4. The differences between the cohorts were found to be insignificant, which is not surprising given that the period of births of women included in these models was smaller than those considered above. However, the models in Table 4 showed that the differences between women living in urban and rural areas and between women in different education groups did not become weaker in the younger cohorts. The contrast between accepting and not accepting domestic violence became even sharper, and the ethnic differences reported in Table 2 persisted. Women who were using the internet daily had significantly lower risks of entering a first union, and women who had a job at the time of the survey had risks of entering a first union that were almost three times lower than they were for women who did not have a job. 
Table 4:

Risks of transitioning to a first union, women born in 1989-98 (Cox regression)

\begin{tabular}{|c|c|c|c|c|c|}
\hline & (1) & (2) & (3) & (4) & (5) \\
\hline \multicolumn{6}{|l|}{ Birth cohort } \\
\hline 1985-89 & 1 & 1 & 1 & 1 & 1 \\
\hline 1990-94 & 0.917 & 0.909 & 0.880 & 1.062 & 0.976 \\
\hline $1995-98$ & 0.746 & 0.726 & 0.634 & 0.909 & 0.778 \\
\hline \multicolumn{6}{|l|}{ Area } \\
\hline Urban & 1 & 1 & 1 & 1 & 1 \\
\hline Rural & $1.632^{* * *}$ & $1.600^{* * *}$ & $1.439^{* * *}$ & $1.464^{* * *}$ & $1.282^{* * *}$ \\
\hline \multicolumn{6}{|l|}{ Education } \\
\hline No higher education & 1 & 1 & 1 & 1 & 1 \\
\hline Higher education & $0.466^{* * *}$ & $0.486^{* * *}$ & $0.467^{* * *}$ & $0.591^{* * *}$ & 1.126 \\
\hline \multicolumn{6}{|l|}{ Ethnicity } \\
\hline Kyrgyz & & 1 & 1 & 1 & 1 \\
\hline Russian & & $0.581^{* * *}$ & $0.675^{*}$ & $0.671^{*}$ & 0.792 \\
\hline Uzbek & & $1.583^{* * *}$ & $1.626^{* * *}$ & $1.321^{* * *}$ & 1.084 \\
\hline \multicolumn{6}{|c|}{ Accepts domestic violence } \\
\hline No & & & & & 1 \\
\hline Yes & & & & & $1.395^{* * *}$ \\
\hline \multicolumn{6}{|l|}{ Currently has a job } \\
\hline No & & & 1 & & 1 \\
\hline Yes & & & $0.351^{* * *}$ & & $0.393^{* * *}$ \\
\hline \multicolumn{6}{|l|}{ Access to internet } \\
\hline No & & & & 1 & 1 \\
\hline Less than once a weel & & & & 1.259 & 1.366 \\
\hline At least once a week & & & & 1.198 & 1.460 \\
\hline Almost every day & & & & $0.541^{* *}$ & 0.736 \\
\hline Chi-square & $117.017^{* * *}$ & $139.227^{* * *}$ & $200.351^{* * *}$ & $223.915^{* * *}$ & $323.334^{* * *}$ \\
\hline $\begin{array}{l}-2 \log \\
\quad \text { Likelihood }\end{array}$ & 6384.136 & 6363.387 & 6293.260 & 6291.976 & 6200.985 \\
\hline$N$ & 1482 & 1482 & 1482 & 1482 & 1482 \\
\hline
\end{tabular}

\section{Discussion}

Our analysis has confirmed that the trend towards delaying motherhood did not start in Kyrgyzstan among women born in the 1960s to the early 1990s in the period up to 2014. The higher risks of entering a first union, and especially of having a first birth in a union, observed among the youngest birth cohorts seem 
to point to a "rejuvenation" in the timing of the two events, and thus suggest a new tendency of "advancing" motherhood among younger women. Note that similar Cox regression analysis undertaken for some other post-Soviet countries that produced firm evidence of fertility postponement showed a gradual lowering of the risks of both events among the cohorts born in the 1980s and the 1990s (see, e.g., Mitrofanova (2017) for Russia). In Kyrgyzstan, a significant lowering of these risks compared to those among the older birth cohorts was detected for the 1980-84 birth cohort only. For the women of that particular cohort, this finding is expected, because they entered their reproductive period in the second half of the 1990s or in the early 2000s, when the economic and political situation in the country was still very uncertain. However, this postponement trend has not touched later cohorts in Kyrgyzstan.

The analysis has also shown that a number of social-economic parameters had significant effects on the likelihood of transitioning to a first marriage and a first birth in the cohorts under study. Our finding that higher education was associated with a lower likelihood of both entering a first union and having a first birth confirmed our Hypothesis 1, and is in agreement with similar results for other developing countries (see Section 2). We also found that women's employment had a similar effect, although we could analyse its influence among the younger cohorts only. Our findings on the effects of women's education and labour market position support our first hypothesis. Our observation that the wealthiest women had a lower risk of entering a first union may be partly related to the higher education levels in this social group. However, since education retained its significance when considered together with the wealth index (Model 5 of Table 2), it is possible that some other characteristics of the richest quintile of women supported the postponement of the first union among this social group. Interestingly, the wealth index was found to be insignificant for the likelihood of transitioning to motherhood, which suggests that the fertility behaviour of married women in the "upper class" of Kyrgyzstan society did not differ radically from that of their counterparts in other strata.

Although our data allowed us to include only a few indicators on generational or gender relations, our results showed that these indicators influenced union formation and first birth timing in the ways Hypothesis 2 suggested. Our finding that the risks of both events were higher among women who accepted domestic violence showed that earlier transitions were characteristic of women who indicated that they see the position of the wife in the family as strongly subordinate. The differences in the timing of union and motherhood between women with different views on gender norms and gender relations became even stronger among the younger generations. This sharper differentiation of family behaviour by gender norms was, however, shown to be accompanied by a decreasing share of women accepting domestic violence among the younger cohorts. In the MICS2014 sample, the proportion of women who said they consider it acceptable for a husband to beat his wife under some conditions gradually declined from the 1975-79 birth cohort (42.4\%) to the 1995-98 birth cohort (23.5\%). As accepting domestic violence became a "minority" 
view, it emerged as an important factor in the early transition to marriage and motherhood.

Whereas the attitude towards domestic violence was an ideational factor, the age gap between partners appears to have signalled the actual gender asymmetries in a woman's family. The significant relationship we found between a larger age gap and a higher risk of having a first child confirmed our hypothesis that greater gender asymmetries supported earlier birth timing, although the risk ratios were shown to have changed only slightly with each annual increase in the gap (Models 5 and 6 of Table 3). The age gap between the partners and its effects were not found to have changed much between the cohorts included in our study, with the average age gap being at a rather high level of 4.5 years, according to the MICS2014 data. Thus, our analysis suggested that there was a family organisation parameter that was stable across cohorts, and that at least moderately supported earlier family formation.

The lower propensity for entering the first union found among women of the younger cohorts who were using the internet daily can be interpreted in light of our Hypothesis 2 as well, provided we assume that more frequent internet use indicates that a woman's family members were exercising less control over her. However, the differences in the frequency of internet use could also reflect different levels of network connection quality in different parts of the country.

Our hypothesis concerning ethnicity (Hypothesis 3 ) was generally confirmed, as the parameter of native language of household head, which was used as the proxy for ethnicity, was found to be significant for both the first union and the first birth risks. For both events, the risks were highest for Uzbeks and lowest for Russians. However, the differences between the different ethnicities were shown to be stronger for the first union than for the first birth. In addition, the differences in the likelihood of transitioning to a first birth were found to be significant between Uzbek and Kyrgyz women, but not between Russian and Kyrgyz women. Although we were unable to identify the factors that underlie these ethnic differences based on the available data, we were able to relate the earlier timing of unions and births among Uzbek and Kyrgyz women to the lower social status of women in these ethnic groups. Descriptive data from Table 1 support this view, as compared to both Kyrgyz and Uzbek women, Russian women had higher levels of educational attainment, employment, and daily internet access, and were more likely to reject domestic violence. Kyrgyz women, in turn, had much higher levels of education and daily internet access than Uzbek women. The results also showed that the share of women accepting domestic violence was highest among Uzbeks, at almost 50\%. However, it is important to note that ethnicity was significant in the models in which these parameters were independently included. Therefore, if the inter-ethnic differences really can be explained by different degrees of family "conservatism", some other elements of that "conservatism" probably come into play that are not observable in our data.

Overall, our research on Kyrgyzstan provides insights into a society that experienced a shift towards early entry into the first union and motherhood among younger generations - which seems to contrast with the delayed family transitions observed 
in highly developed countries and in the majority of developing countries. Our study showed that the changes in the timing of the first union and of the first birth within a union did not need to occur completely in parallel across generations. We also found that the factors driving the earlier timing of these two events could differ. These results suggest that when studying developing countries, it is important to model the transitions to the first union and the first birth separately. Especially in countries like Kyrgyzstan, which has a negligible level of out-of-union fertility, this separate modelling allows analysts to decompose changes in first birth patterns into the effects of union formation and of the first birth within a union. We have demonstrated that the earlier timing of family events was correlated with women having a subordinate position in the family and lower levels of education and employment outside of the household. These findings suggest that fertility timing is dependent upon "traditionalism" in family relations; and, in turn, that future trends in union and birth timing will be influenced by family "(de)traditionalisation". This hypothesis needs to be investigated more thoroughly across countries, which could be complicated by the differences in the measures of generational and gender relations that are available for different developing countries. Finally, our analysis has shown the significance of ethnicity for the timing of family transitions, which cannot be explained away by inter-ethnic differences in a woman's position in her family. This finding calls for broader research on the role of ethnicity in the timing of union formation and motherhood across developing countries.

\section{Acknowledgements}

This paper is an output of a research project implemented as part of the Basic Research Program at the National Research University Higher School of Economics (HSE University).

\section{References}

Agadjanian, V. and P. Dommaraju 2011. Culture, modernization, and politics: Ethnic differences in union formation in Kyrgyzstan. European Journal of Population 27: 79-101. https://doi.org/10.1007/s10680-010-9225-7

Agadjanian, V., P. Dommaraju and L. Nedoluzhko 2013. Economic fortunes, ethnic divides, and marriage and fertility in Central Asia: Kazakhstan and Kyrgyzstan compared. Journal of Population Research 30(3): 197-211. https://doi.org/10.1007/s12546-013-9112-2

Al Zalak, Z. and A. Goujon 2017. Exploring the fertility trend in Egypt. Demographic Research 37(32): 995-1030. https://doi.org/10.4054/DemRes.2017.37.32

Billari, F. C. and D. Philipov 2004. Education and the transition to motherhood: A comparative analysis of Western Europe. European Demographic Research Paper No. 3. Vienna: Vienna Institute of Demography. 
Billari, F. C., H.-P. Kohler, G. Andersson and H. Lundström 2007. Approaching the limit: Long-tern trends in late and very late fertility. Population and Development Review 33(1): 149-170. https://doi.org/10.1111/j.1728-4457.2007.00162.x

Bongaarts, J. 1999. The fertility impact of changes in timing of childbearing in developing world. Population Studies 53(3): 277-289. https://doi.org/10.1080/00324720308088

Bongaarts, J. and G. Feeney 1998. On the quantum and tempo of fertility. Population and Development Review 24(2): 271-291. https://doi.org/10.2307/2807974

Bongaarts, J. and S. Watkins 1996. Social interactions and contemporary fertility transitions. Population and Development Review 22(4): 639-682. https://doi.org/10.2307/2137804

Bongaarts, J., B. S. Mensch and A. C. Blanc 2017. Trends in the age at reproductive transitions in the developing world: The role of education. Population Studies 71(2): 139-154. https://doi.org/10.1080/00324728.2017.1291986

Breierova, L. and E. Duflo 2004. The impact of education on fertility and child mortality: Do fathers really matter less than mothers? Working Paper 10513. National Bureau of Economic Research.

Carmichael, S. 2011. Marriage and power: Age at first marriage and spousal age gap in lesser developed countries. The History of the Family 16(4): 416-436. https://doi.org/10.1016/j. hisfam.2011.08.002

Casterline, J. B., L. Williams and P. McDonald 1986. The age difference between spouses: Variations among developing countries. Population Studies 40(3): 353-374. https://doi. org/10.1080/0032472031000142296

Cetorelli, V. and T. Leone 2012. Is fertility stalling in Jordan? Demographic Research 26(13): 293-318. https://doi.org/10.4054/DemRes.2012.26.13

Denisenko, M., N. Kalmykova and L. Nedoluzhko 2012. Nuptiality and fertility in Kyrgyzstan. Demoscope Weekly, 493-494, 1-22 January 2012 (in Russian). http://www. demoscope.ru/weekly/2012/0493/tema01.php, accessed on 29.01.2020.

Dyson, T. and M. Moore 1983. On kinship structure, female autonomy, and demographic behavior in India. Population and Development Review 9(1): 35-60. https://doi.org/10. 2307/1972894

Ezhegodnik. 2017. Demograficheskij ezhegodnik Kyrgyzskoj Respubliki 2012-2016 [Demographic Yearbook of Kyrgyz Republic]. Bishkek.

Fazle Rabbi, A. M. and M. H. M. Imrul Kabir 2013. Factors influencing age at first birth of Bangladeshi women - a multivariate approach. American Journal of Public Health Research 1(7): 191-195. https://doi.org/10.12691/ajphr-1-7-8

Fédération internationale des droits de l'Homme (FIDH) Kyrgyzstan 2016. Women and children from Kyrgyzstan involved in migration process as the most vulnerable groups (in Russian): https://www.fidh.org/IMG/pdf/rapport_kyrgyzstan_ru-web.pdf

Guilamo-Ramos, V., J. J. Lee, L. M. Kantor, D. S. Levine, S. Baum and J. Johnsen 2015. Potential for using online and mobile education with parents and adolescents to impact sexual and reproductive health. Prevention Science 16(1): 53-60. https://doi.org/10.1007/ s11121-014-0469-z

Hull, T. H. and W. Hartanto 2009. Resolving contradictions in Indonesian fertility estimates. Bulletin of Indonesian Economic Studies 45(1): 61-71. https://doi.org/10.1080/ 00074910902836197 
Ismailbekova, A. 2014. Migration and patrilineal descent: The role of women in Kyrgyzstan. Central Asian Survey 33(3): 375-389, https://doi.org/10.1080/02634937.2014.961305.

Ismailbekova, A. 2016. Constructing the authority of women through custom: Bulak village, Kyrgyzstan. Nationalities papers 44(2): 266-280. https://doi.org/10.1080/00905992.2015. 1081381

Kamal, M. S. M. 2010. Fertility decline in Bangladesh: Understanding the future direction and contribution of demographic components. Journal of Applied Science and Technology 7(1): 99-104.

Kandiyoti, D. 2007. The politics of gender and the Soviet paradox: Neither colonized, nor modern? Central Asian Survey 26(4): 601-623. https://doi.org/10.1080/ 02634930802018521

Lerch, M. 2013. Patriarchy and fertility in Albania. Demographic Research 29(6): 133-166 https://doi.org/10.4054/DemRes.2013.29.6.

Lesthaeghe, R. 2010. The unfolding story of the second demographic transition. Population and Development Review 36(2): 211-251. https://doi.org/10.1111/j.1728-4457.2010. 00328.x

Mason, K. O. 2001. Gender and family systems in the fertility transition. Population and Development Review 27: 160-176.

McDonald P. 2000. Gender equity in theories of fertility transition. Population and Development Review 26(3): 427-439. https://doi.org/10.1111/j.1728-4457.2000.00427.x

Mills, M., R. R. Rindfuss, P. McDonald and E. te Velde 2011. Why do people postpone parenthood? Reasons and social policy incentives. Human Reproduction Update 17(6): 848-860. https://doi.org/10.1093/humupd/dmr026

Mitrofanova, E. 2017. Becoming an adult in France, Estonia and Russia. Higher School of Economics Research Papers Working Papers WP BRP 78/SOC/2017. https://doi.org/10. 2139/ssrn.3078678\%20

Multrie, T. A., T. S. Sayi and I. M. Timæus 2012. Birth intervals, postponement, and fertility decline in Africa: A new type of transition? Population Studies 66(3): 241-258. https://doi.org/10.1080/00324728.2012.701660

Nathan, M., I. Parda and W. Cabella 2016. Diverging patterns of fertility decline in Uruguay. Demographic Research 34(13): 563-586. https://doi.org/10.4054/DemRes.2016.34.20

Nedoluzhko, L. and V. Agadjanian 2010. Marriage, childbearing, and migration in Kyrgyzstan: Exploring interdependencies. Demographic Research 22(7): 159-188. https://doi.org/10.4054/DemRes.2010.22.7

Nedoluzhko, L. and G. Andersson 2007. Migration and first-time parenthood: Evidence from Kyrgyzstan. Demographic Research 17(25): 741-774. https://doi.org/10.4054/DemRes. 2007.17.25

Ngalinda, I. 1998. Age at first birth, fertility, and contraception in Tanzania. Doctoral dissertation, Humboldt University of Berlin, Germany.

Ní Bhrolcháin, M. 1993. East West marriage contrasts, old and new. In European Population II: demographic dynamics, eds A. Blum and J. Rallu, 461-479. Paris: John Libbey Eurotext. 
Ní Bhrolcháin, M. and É. Beaujouan 2012. Fertility postponement is largely due to rising educational enrolment. Population Studies 66(3): 311-327. https://doi.org/10.1080/ 00324728.2012 .697569

Ouadah-Bedidi, Z. and Vallin Jacques. 2012. Fertility and population policy in Algeria: Discrepancies between planning and outcomes. Population and Development Review 38: 179-196.

Philipov, D., Z. Speder and F. C. Billari 2006. Soon, later, or ever? The impact of anomie and social capital on fertility intension in Bulgaria (2002) and Hungary (2001). Population Studies 60(3): 289-308. https://doi.org/10.1080/00324720600896080

Rindfuss R., A. Parnell and C. Hirschman 1983. The timing of entry into motherhood in Asia: A comparative perspective. Population Studies 37: 253-272. https://doi.org/10.1080/ 00324728.1983.10408750

Salway, S. M. 2007. Economic activity among UK Bangladeshi and Pakistani women in the 1990s: Evidence for continuity or change in the family resources survey. Journal of Ethnic and Migration Studies 33(5): 825-847, https://doi.org/10.1080/13691830701359256

Sobotka, T. 2008. The diverse faces of the second demographic transition in Europe. Demographic Research 19(8): 171-224. https://doi.org/10.4054/DemRes.2008.19.8

Sobotka, T. 2010. Shifting parenthood to advanced reproductive ages: Trends, causes and consequences. In A young generation under pressure? ed J. C. Tremmel, 129-154. Berlin Heidelberg: Springer Verlag.

Speder, Z. 2005. The rise of cohabitation as first union and some neglected issues of recent demographic developments in Hungary. Demográfia (English edition) 48: 77-103.

Spoorenberg, T. 2013. Fertility changes in Central Asia since 1980. Asian Population Studies 9: 50-77. https://doi.org/10.1080/17441730.2012.752238

Spoorenberg, T. 2015. The onset of fertility transition in Central Asia. Population 72(3): 473-504.

Spoorenberg, T. 2017. After fertility's nadir? Ethnic differentials in parity-specific behaviours in Kyrgyzstan. Journal of Biosocial Science 49(S1): 62-73. https://doi.org/10.1017/ S0021932017000335

State migration service under the Kyrgyz government http://ssm.gov.kg/

Tishkov, V. A. 1994. Russians in Central Asia. In Russians in the near abroad, eds V. I. Kozlov and E. A. Shervoud. Moscow: Institute of Ethnology and Anthropology of Russian Academy of Science (in Russian).

Tromble, R. 2014. Securitizing Islam, securitizing ethnicity: The discourse of Uzbek radicalism in Kyrgyzstan. East European Politics 30(4): 526-547. https://doi.org/10. 1080/21599165.2014.950417

Van den Kaa, D. J. 1987. Europe's second demographic transition. Population Bulletin 42(1): $1-59$. 


\section{Appendix}

Table A.1:

Statistic tests showing the significance of differences in the cumulative probability of remaining childless between neighbouring birth cohorts in Kyrgyzstan according to the MICS 2014 and the DHS2012

\begin{tabular}{|c|c|c|c|c|c|c|}
\hline & \multicolumn{3}{|c|}{ MICS2014 } & \multicolumn{3}{|c|}{ DHS2012 } \\
\hline & Log Rank & Breslow & $\begin{array}{c}\text { Tarone- } \\
\text { Ware }\end{array}$ & Log Rank & Breslow & $\begin{array}{c}\text { Tarone- } \\
\text { Ware }\end{array}$ \\
\hline $\begin{array}{l}1970-74 \text { to } \\
1965-69\end{array}$ & 0.640 & 1.689 & 1.083 & $4.719^{* *}$ & $18.544^{* * *}$ & $11.968^{* * *}$ \\
\hline $\begin{array}{l}1975-79 \text { to } \\
1970-74\end{array}$ & 1.401 & 2.648 & 2.005 & 1.257 & 2.023 & 1.366 \\
\hline $\begin{array}{l}1980-84 \text { to } \\
1975-79\end{array}$ & $6.419^{* * *}$ & $22.183^{* * *}$ & $15.808^{* * *}$ & $18.135^{* * *}$ & $25.371^{* * *}$ & $22.594^{* * *}$ \\
\hline $\begin{array}{l}1985-89 \text { to } \\
1980-84\end{array}$ & $4.187^{* *}$ & 0.700 & 2.106 & 0.689 & $5.300^{* *}$ & $2.768^{*}$ \\
\hline $\begin{array}{l}1990-94 \text { to } \\
1985-89\end{array}$ & $14.272^{* * *}$ & $22.896^{* * *}$ & $19.673^{* * *}$ & $9.379^{* * *}$ & $12.154^{* * *}$ & $11.102^{* * *}$ \\
\hline
\end{tabular}

Source: Computed on the MICS and the DHS database.

Open Access This article is published under the terms of the Creative Commons Attribution 4.0 International License (https://creativecommons.org/licenses/by/4.0/) that allows the sharing, use and adaptation in any medium, provided that the user gives appropriate credit, provides a link to the license, and indicates if changes were made. 
